\title{
A cyclooxygenase-2 (COX-2) inhibitor compared with dexamethasone in a survival study of rats with intracerebral $9 \mathrm{~L}$ gliosarcomas
}

\author{
Jana Portnow, Samia Suleman, Stuart A. Grossman, ${ }^{1}$ Susan Eller, and Kathryn Carson
}

The Johns Hopkins Oncology Center, 401 North Broadway, Baltimore, MD 21231

\begin{abstract}
Although dexamethasone is very effective for controlling peritumoral cerebral edema, it is associated with distressing side effects that decrease the quality of life for many patients. One potential mechanism to explain the ability of dexamethasone to repair blood-brain barrier dysfunction is through the inhibition of cyclooxygenase-2 (COX-2). The purpose of this study was to determine in a rat brain tumor model whether SC-236, a selective COX-2 inhibitor, is as effective as dexamethasone. Twenty-nine adult male Fischer 344 rats were implanted with intracerebral 9L gliosarcomas and divided into 3 treatment groups. One group $(n=9)$ served as controls, another $(n=9)$ was treated with dexamethasone ( $3 \mathrm{mg} / \mathrm{kg}$ p.o. daily), and a third group ( $n=$ 11) received SC-236 (3 mg/kg p.o. daily). A survival study was performed. The median survival in the control group was 16 days, compared with 23 days for the dexamethasone group and 23 days for the COX-2 inhibitor group. Kaplan-Meier analysis on pairwise group comparisons showed improved survival that was statistically significant for each treatment group compared with the control group (log-rank test $P=0.009$ for dexamethasone to control and $P=0.005$ for COX-2 to control), and no significant difference in survival for the COX-2 compared with dexamethasone (log-rank
\end{abstract}

\section{Received 26 April 2001, accepted 23 August 2001.}

${ }^{1}$ Address correspondence and reprint requests to Stuart A. Grossman, The Johns Hopkins Oncology Center, Bunting-Blaustein Cancer Research Bldg., Rm. G93, 1650 Orleans St., Baltimore, MD 21231 1000.

${ }^{2}$ Abbreviations used are as follows: COX-2, cyclooxygenase-2; NSAIDs, nonsteroidal antiinflammatory drugs. test $P=0.2$ ). These results suggest that a selective COX-2 inhibitor appears to be as effective as dexamethasone in prolonging survival in a rat brain tumor model. Neuro-Oncology 4, 22-25, 2002 (Posted to Neuro-Oncology [serial online], Doc. 01-025, November 15, 2001. URL <neuro-oncology.mc.duke.edu>)

V asogenic cerebral edema typically accompanies the growth of brain tumors. This edema results from the production of vasogenic permeability factors by the tumor (Bruce et al., 1987; Criscuolo et al., 1988) that cause widening of the tight endothelial cell junctions of the blood-brain barrier. Capillaries become fenestrated and an increased number of pinocytotic vesicles appear (Long, 1979). The result of this increased capillary permeability is a net influx of plasma constituents from the blood into surrounding brain tissue (Klatzo, 1972).

Dexamethasone has traditionally been used to treat this type of cerebral edema and has improved neurologic function (Galicich and French, 1961) and survival in brain tumor patients (Posner, 1975). In 1966, the morphologic effect of dexamethasone on cerebral edema was first described with the use of electron microscopy (Long et al., 1966). The investigators examined surgical specimens from the brains of 15 patients with a variety of CNS tumors that had been treated with dexamethasone. They found that vasogenic cerebral edema results in ultrastructural changes, such as enlargement of pericapillary astrocyte processes and increased extracellular space in the white matter with axon deformity, which dexamethasone can completely reverse. Although this study and others (Hedley-White and Hsu, 1986; Olson et al., 1988) have shown that corticosteroids can repair a disrupted blood-brain barrier, the mechanism by which they accomplish this is not clear.

Although dexamethasone is effective in controlling peritumoral brain edema, often, intolerable side effects 
develop, particularly because high doses of dexamethasone are frequently required for long periods of time (Koehler, 1995; Weissman et al., 1987). Examples of such side effects that significantly decrease quality of life for patients include weight gain, dyspepsia, sleep disturbances, glucose intolerance, emotional lability sometimes resulting in psychosis, increased susceptibility to infection, osteoporosis, and a progressive proximal myopathy that can make it impossible for patients to ambulate.

Studies of dexamethasone have determined that one of its mechanisms of action is inhibition of COX-2 $2^{2}$ expression (Masferrer et al., 1992, 1994). Cyclooxygenase is the ratelimiting enzyme involved in the production of prostaglandins from arachidonic acid. It exists as two isoforms: COX-1, the constitutive form that is expressed in most tissues and has a homeostatic function, and COX-2, the inducible form of the enzyme that is usually only present in tissues at significant levels when there is inflammation (Masferrer et al., 1996). The first selective COX-2 inhibitors, a new class of NSAIDs, received Food and Drug Administration approval in 1998 for the treatment of rheumatoid arthritis and osteoarthritis. These novel drugs have the same anti-inflammatory and pain-relieving properties as other NSAIDs, but have a more favorable toxicity profile because they do not interfere with platelet function and are less likely to cause gastrointestinal bleeding (Schrefer, 2000). Because selective COX-2 inhibitors have a mechanism of action similar to dexamethasone, but have a better toxicity profile, the purpose of this study was to begin investigating whether it is possible to use a selective COX-2 inhibitor instead of dexamethasone for controlling peritumoral cerebral edema.

\section{Materials and Methods}

This study involved the use of live rats and was approved by the Institutional Animal Care and Use Committee of The Johns Hopkins University School of Medicine.

\section{Placement of Intracerebral Tumors}

Adult male Fischer 344 rats were anesthetized by i.p. injections of ketamine $(90 \mathrm{mg} / \mathrm{kg})$ and xylazine $(10 \mathrm{mg} / \mathrm{kg})$. The scalp of each rat was shaved and cleaned with alcohol. A midline incision was made, and the scalp, along with the underlying tissue, was retracted. Using a Dremmel drill (Emerson Electric Co., Racine, Wis.), a 2-mm burr hole was made stereotactically through the skull at $1 \mathrm{~mm}$ posterior to the bregma and $4 \mathrm{~mm}$ lateral to the sagittal suture over the right cerebral hemisphere. A $1.5-\mathrm{mm} \times 1.5-\mathrm{mm}$ piece of tumor from a s.c. 9L gliosarcoma grown in a carrier rat was placed through the burr hole just below the surface of the brain. A piece of Gelfoam was inserted as well. The incision was closed with surgical staples.

\section{Treatment Groups}

The rats were randomly divided into 3 treatment groups after tumor implantation. The first group, consisting of 9 rats, served as controls. They received no further intervention and were observed until they died or developed neurologic deterioration, at which time they were killed.

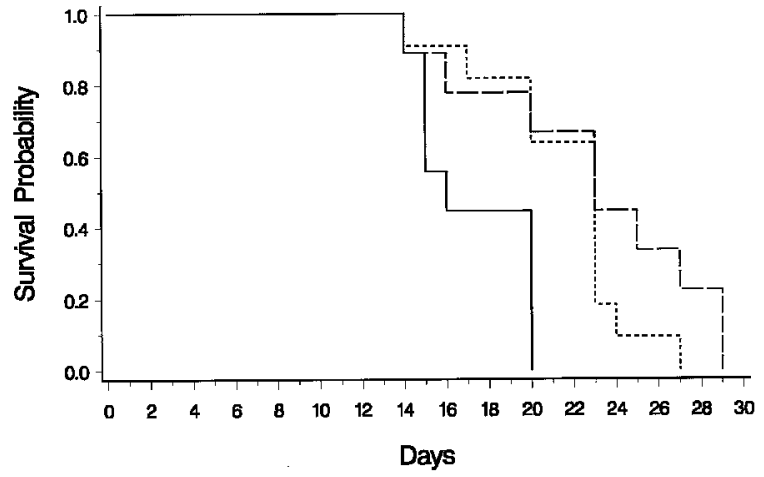

Fig. 1. Kaplan-Meier survival curves. Kaplan-Meier survival analysis was used to compare the 3 groups of rats: control group (solid line), dexamethasone group (broken line), COX-2 group (dashed line). Survival was significantly improved for the dexamethasone group (logrank $P=0.009$ ) and the COX-2 group (log-rank $P=0.005)$ when compared with the control group. There was no significant difference in survival for the COX-2 group when compared with the dexamethasone group $(\log$-rank $P=0.2)$.

The second group, consisting of 9 rats, was gavaged daily with dexamethasone $(3 \mathrm{mg} / \mathrm{kg})$ beginning the day after tumor implantation. They were given dexamethasone daily until they died or were killed. Similarly, the third group, composed of 11 rats, was gavaged daily with SC-236 (3 mg/ $\mathrm{kg}$ ), a COX-2 inhibitor, until they died or were killed.

\section{Results}

Kaplan-Meier survival analysis was used to compare the 3 groups. The median length of survival was $16(95 \%$ confidence interval, 15-20) days in the control group compared with 23 (95\% confidence interval, 20-27) days in the dexamethasone group and 23 (95\% confidence interval, 20-23) days in the COX-2 inhibitor group (Fig. 1). The log-rank chi-square result comparing survival across the 3 groups was significant $(P=0.002)$. Pairwise group comparisons were performed. Survival was significantly improved for the dexamethasone group $(\log$-rank $P=0.009)$ and the COX-2 group (log-rank $P=$ $0.005)$ when compared with the control group. There was no significant difference in survival for the COX-2 group when compared with the dexamethasone group $(\log$-rank $P=0.2)$. The rat surviving the longest in the control group lived 21 days compared with 30 days in the dexamethasone group and 28 days in the COX-2 inhibitor group.

Table 1. Cause of death in each group of rats

\begin{tabular}{lccc} 
& $\begin{array}{c}\text { Control } \\
\text { group } \\
(n=9)\end{array}$ & $\begin{array}{c}\text { Dexamethasone } \\
\text { group } \\
(n=9)\end{array}$ & $\begin{array}{c}\text { COX-2 } \\
\text { inhibitor } \\
\text { group }(n=11)\end{array}$ \\
\hline Killed (\%) & $7(77)$ & $5(56)$ & $7(64)$ \\
Natural (\%) & $2(23)$ & $4(44)$ & $4(36)$ \\
\hline
\end{tabular}


As detailed above, all of the rats were followed until they died or developed neurologic deterioration, at which time they were killed. Criteria for putting them to death were consistently applied to all of the groups. A similar number of animals in each treatment group were killed (Table 1). Autopsies done on the brains of the rats revealed the presence of large tumors in the region of tumor implantation among all 3 groups of rats.

\section{Discussion}

Peritumoral cerebral edema affects almost all patients with primary brain tumors at some point during the course of their illness. With the use of a rabbit brain tumor model, it has been demonstrated that dexamethasone can significantly delay the development of peritumoral cerebral edema and that, once dexamethasone is discontinued, the cerebral edema recurs rapidly (Weissman and Grossman, 1988). Although dexamethasone is very effective for treating this medical problem, its use often results in debilitating side effects. As a result, other drugs with similar mechanisms of action have been investigated as possible alternatives to dexamethasone for the treatment of vasogenic cerebral edema. NSAIDs inhibit both COX-1 and, similar to dexamethasone, COX-2 isoenzymes. Studies looking at the treatment of peritumoral cerebral edema with NSAIDs have produced conflicting results. Some investigators have shown that NSAIDs, such as ibuprofen, can decrease tumor-associated protein extravasation in a preclinical glioma model (Reichman et al., 1986) and can produce clinical improvement in some patients with peritumoral cerebral edema (Del Maestro and Mattar, 1988). However, another study using the VX2 rabbit brain tumor model did not confirm the anticerebral edema effect from NSAIDs (Weissman and Stewart, 1988). SC-236 is a selective COX-2 inhibitor and has a mechanism of action similar to dexamethasone's. This is the first study to show that a new selective COX-2 inhibitor appears to be as effective as dexamethasone for prolonging survival in a rat brain tumor model.

Studies by other investigators have shown that COX-2 is overexpressed in many tumors (Gupta et al., 2000; Masferrer et al., 2000; Sano et al., 1995; Tucker et al., 1999), including gliomas (Joki et al., 2000). Several preclinical studies have shown that COX-2 inhibitors also exhibit an antitumor effect, although the precise mechanism of action is not clear. Theories include inhibition of angiogenesis (Masferrer et al., 2000; Milas et al., 1999) and induction of apoptosis (Elder et al., 1997; Liu et al., 1998; Sawaoka et al., 1998). As a result, it is possible that the improved survival in the COX-2 inhibitor group compared with the control group in our study is due to the direct antitumor effect of the COX-2 inhibitor. However, when comparing the COX-2 inhibitor group to the group of rats that received the corticosteroid, which is not believed to have any direct antitumor activity against gliomas (Green et al., 1983), one sees that survival was similar, and at autopsy, large tumors were found in both groups. Therefore, we suspect that the survival benefit seen with SC-236 in this study is more likely due to its anti-edema activity rather than to any antitumor effect of the selective COX-2 inhibitor.
Although this exploratory study did not include an attempt to quantify the amount of cerebral edema present in the brain of each animal, the results suggest that the ability of dexamethasone to control cerebral edema may occur through its selective inhibition of COX-2 expression. As stated previously, the exact mechanism by which dexamethasone repairs a disrupted blood-brain barrier is unknown. Some investigators have postulated that dexamethasone decreases cerebral edema by blocking the metabolism of arachidonic acid, which plays a role in increasing the permeability of the blood-brain barrier (Unterberg et al., 1986; Unterberg et al., 1987) or by incorporating steroid molecules into the hydrophobic portion of the endothelial cell membrane, thereby stabilizing the membrane (Casanova, 1984). Others believe that rather than causing a direct decrease in production of edema, dexamethasone indirectly improves cerebral edema by promoting its reabsorption. Dexamethasone can inhibit the choroid plexus from producing cerebrospinal fluid. This results in the creation of an increased pressure gradient for extravasated fluid to move into the cerebrospinal fluid (Pappius, 1975; Schwartz et al., 1972). The results of our study suggest that a selective COX-2 inhibitor is as effective as dexamethasone for prolonging survival in rats with intracerebral tumors. These findings lend support to the first theory that dexamethasone directly decreases vasogenic cerebral edema through its antiinflammatory properties, namely, COX-2 inhibition.

Although the results of this preliminary study indicate that a selective COX-2 inhibitor may be as effective as dexamethasone for controlling peritumoral cerebral edema, it is beyond the scope of this study to show that such use of a selective COX-2 inhibitor is associated with fewer side effects. Intuitively, this would seem so, as the only major toxicities from COX-2 inhibitors are renal dysfunction and risk of gastrointestinal bleeding (Schrefer, 2000) compared with the long list of debilitating side effects produced by dexamethasone. Emotional lability, sleep disturbance, and proximal myopathy are examples of side effects that are best compared in humans. Currently, a pilot study involving the use of celecoxib, a commercially available selective COX-2 inhibitor, to control cerebral edema in patients with brain tumors is being conducted at The Johns Hopkins Oncology Center. The results of this pilot study could serve as a basis for a larger randomized study that would directly compare COX-2 inhibitors with dexamethasone in terms of efficacy and toxicity for the treatment of cerebral edema in patients with brain tumors.

In summary, this preliminary study has shown that a selective COX-2 inhibitor is as effective as dexamethasone for prolonging survival in a rat brain tumor model. Further study of COX-2 inhibitors as alternatives to dexamethasone for the treatment of cerebral edema in patients with brain tumors is warranted. Such studies could result in a significant improvement in the quality of life for patients with these devastating tumors.

\section{Acknowledgments}

Gary Gordon, M.D., Ph.D., at Pharmacia Corporation, St. Louis, Missouri, supplied the COX-2 inhibitor, SC236 , for this study. 


\section{References}

Bruce, J.N., Criscuolo, G.R., Merrill, M.J., Moquin, R.R., Blacklock, J.B., and Oldfield, E.H. (1987) Vascular permeability induced by protein product of malignant brain tumors: Inhibition by dexamethasone J. Neurosurg. 67, 880-884.

Casanova, M.F. (1984) Vasogenic edema with intraparenchymatous expanding mass lesions: A theory on its pathophysiology and mode of action of hyperventilation and corticosteroids. Med. Hypotheses 13, 439-450.

Criscuolo, G.R., Merrill, M.J., and Oldfield, E.H. (1988) Further characterization of malignant glioma-derived vascular permeability factor. J. Neurosurg. 69, 254-262.

Del Maestro, R.F., and Mattar, A.G. (1988) The influence of ibuprofen on patients with peritumoral edema. Can. J. Neurol. Sci. 15, 227. (Abstract)

Elder, D.J., Halton, D.E., Hague, A., and Paraskeva, C. (1997) Induction of apoptotic cell death in human colorectal carcinoma cell lines by a cyclooxygenase-2 (COX-2)-selective nonsteroidal anti-inflammatory drug: Independence from COX-2 protein expression. Clin. Cancer Res. 3 , 1679-1683.

Galicich, J.H., and French, L.A. (1961) Use of dexamethasone in the treatment of cerebral edema resulting from brain tumors and brain surgery. Amer. Pract. 12, 169-174.

Green, S.B., Byar, D.P., Walker, M.D., Pistenmaa, D.A., Alexander, E., Jr., Batzdorf, U., Brooks, W.H., Hunt, W.E., Mealey, J., Jr., Odom, G.L., Paoletti, P., Ransohoff, J., II, Robertson, J.T., Selker, R.G., Shapiro, W.R., Smith, K.R., Jr., Wilson, C.B., and Strike, T.A. (1983) Comparisons of carmustine, procarbazine, and high dose methylprednisolone as additions to surgery and radiotherapy for the treatment of malignant glioma. Cancer Treat. Rep. 67, 121-132.

Gupta, S., Srivastava, M., Ahmad, N., Bostwick, D.G., and Mukhtar, H. (2000) Over-expression of cyclooxygenase-2 in human prostate adenocarcinoma. Prostate 42, 73-78.

Hedley-White, E.T., and Hsu, D.W. (1986) Effect of dexamethasone on bloodbrain barrier in the normal mouse. Ann. Neurol. 19, 373-377.

Joki, T., Heese, O., Nikas, D.C., Bello, L., Zhang, J., Kraeft, S.K., Seyfried, N.T., Abe, T., Chen, L.B., Carroll, R.S., and Black, P.M. (2000) Expression of cyclooxygenase-2 (COX-2) in human glioma and in vitro inhibition by a specific COX-2 inhibitor, NS-398. Cancer Res. 60, 4926-4931.

Klatzo, I. (1972) Pathophysiological aspects of brain edema. In: Reulen, H.J., and Schurmann, K. (Eds.), Steroids and Brain Edema. New York: SpringerVerlag. pp. 1-8.

Koehler, P.J. (1995) Use of corticosteroids in neuro-oncology. Anticancer Drugs 6, 19-33.

Liu, X.H., Yao, S., Kirschenbaum, A., and Levine, A.C. (1998) NS398, a selective cyclooxygenase- 2 inhibitor, induces apoptosis and down-regulates bcl-2 expression in LNCaP cells. Cancer Res. 58, 4245-4249.

Long, D.M. (1979) Capillary ultrastructure in human metastatic brain tumors. J. Neurosurg. 51, 53-58.

Long, D.M., Hartmann, J.F., and French, L.A. (1966) The response of human cerebral edema to glucosteroid administration: An electron microscopic study. Neurology 16, 521-528.

Masferrer, J.L., Seibert, K., Zweifel, B., and Needleman, P. (1992) Endogenous glucocorticoids regulate an inducible cyclooxygenase enzyme. Proc. Natl. Acad. Sci. U. S. A. 89, 3917-3921.

Masferrer, J.L., Zweifel, B.S., Manning, P.T., Hauser, S.D., Leahy, K.M., Smith, W.G., Isakson, P.C., and Seibert, K. (1994) Selective inhibition of inducible cyclooxygenase- 2 in vivo is anti-inflammatory and non-ulcerogenic. Proc.
Natl. Acad. Sci. U. S. A. 91, 3228-3232.

Masferrer, J.L., Isakson, P.C., and Seibert, K. (1996) Cyclooxygenase-2 inhibitors: A new class of anti-inflammatory agents that spare the gastrointestinal tract. Gastroenterol. Clin. North Am. 25, 363-372.

Masferrer, J.L., Leahy, K.M., Koki, A.T., Zweifel, B.S., Settle, S.L., Woerner, B.M., Edwards, D.A., Flickinger, A.G., Moore, R.J., and Seibert, K. (2000) Antiangiogenic and antitumor activities of cyclooxygenase- 2 inhibitors. Cancer Res. 60, 1306-1311.

Milas, L., Kishi, K., Hunter, N., Mason, K., Masferrer, J.L., and Tofilon, P.J. (1999) Enhancement of tumor response to $\gamma$-radiation by an inhibitor of cyclooxygenase-2 enzyme. J. Natl. Cancer Inst. 91, 1501-1504.

Olson, J.J., Poor, M.M., and Beck, D.W. (1988) Methylprednisolone reduces the bulk flow of water across an in vitro blood-brain barrier. Brain Res. 439, 259-265.

Pappius, H.M. (1975) Normal and pathological distribution of water in brain. In: Cserr, H.F., Fenstermacher, J.D., and Frencl, V. (Eds.), Fluid Environment of the Brain. San Diego: Academic Press. pp.183-199.

Posner, J.B., and Shapiro, W.R. (1975) Brain tumor: Current status of treatment and its complications. Arch. Neurol. 32, 781-784.

Reichman, H.R., Farrell, C.L., and Del Maestro, R.F. (1986) Effects of steroids and nonsteroidal anti-inflammatory agents on vascular permeability in a rat glioma model. J. Neurosurg. 65, 233-237.

Sano, H., Kawahito, Y., Wilder, R.L., Hashiramoto, A., Mukai, S., Asai, K., Kimura, S., Kato, H., Kondo, M., and Hla, T. (1995) Expression of cyclooxygenase-1 and -2 in human colorectal cancer. Cancer Res. 55, 3785-3789.

Sawaoka, H., Kawano, S., Tsuji, S., Tsuji, M., Gunawan, E.S., Takei, Y., Nagano, K., and Hori, M. (1998) Cyclooxygenase-2 inhibitors suppress the growth of gastric cancer xenografts via induction of apoptosis in nude mice. Am. J. Physiol. 274, G1061-G1067.

Schrefer, J., (Ed.) (2000) Mosby's GenRx'TM, Tenth edition. St. Louis: Mosby Inc.

Schwartz, M.L., Tator, C.H., and Hoffman, H.J. (1972) The uptake of hydrocortisone in mouse brain and ependymoblastoma. J. Neurosurg. 36, 178-183.

Tucker, O.N., Dannenberg, A.J., Yang, E.K., Zhang, F., Teng, L., Daly, J.M., Soslow, R.A., Masferrer, J.L., Woerner, B.M., Koki, A.T., and Fahey, T.J., III (1999) Cyclooxygenase-2 expression is up-regulated in human pancreatic cancer. Cancer Res. 59, 987-990.

Unterberg, A., Dautermann, C., Baethmann, A., and Muller-Esterl, W. (1986) The kallikrein-kinin system as mediator in vasogenic brain edema. Part 3 : Inhibition of the kallikrein-kinin system in traumatic brain swelling. J. Neurosurg. 64, 269-276.

Unterberg, A., Wahl, M., Hammersen, F., and Baethmann, A. (1987) Permeability and vasomotor response of cerebral vessels during exposure to arachidonic acid. Acta Neuropathol. 73, 209-219.

Weissman, D.E., and Grossman, S.A. (1988) A model for quantitation of peritumoral brain edema. J. Neurosci. Methods 23, 207-210.

Weissman, D.E., and Stewart, C. (1988) Experimental drug therapy of peritumoral brain edema. J. Neurooncol. 6, 339-342.

Weissman, D.E., Dufer, D., Vogel, V., and Abeloff, M.D. (1987) Corticosteroid toxicity in neuro-oncology patients. J. Neurooncol. 5, 125-128. 